\title{
Experimental study on LBL beams
}

\author{
Chenjie Zhao ${ }^{1}$, Xiaohong Xiong ${ }^{2, *}$, Zhenhua Xiong ${ }^{2, *}$, Kangwen $\mathrm{Wu}^{1}$, Zhen $\mathrm{Cao}^{1}$, Miao Shao ${ }^{1}$, Tongwei Cao ${ }^{1}$, Haoran \\ Dong ${ }^{1}$, Jieying Ding ${ }^{1}$, Chenge Zhao ${ }^{1}$, Yuxuan Xie ${ }^{1}$, Xue Jia ${ }^{1}$, Baofeng Liu ${ }^{1}$, Can Liu ${ }^{1}$, Langkun Jiang ${ }^{1}$, Wenfeng Liu ${ }^{3}$, \\ Dongdong $\mathrm{Wei}^{4}$, Conggan Yuan ${ }^{4}$, and Xinjie $\mathrm{Li}^{1}$ \\ ${ }^{1}$ College of Civil Engineering, Nanjing Forestry University, Nanjing 210037, China \\ ${ }^{2}$ Ganzhou Sentai Bamboo Company LTD, Ganzhou 341001, China \\ ${ }^{3}$ Jiangsu Fashion Safety Monitoring Consulting Co. LTD, Zhenjiang 212009, China \\ ${ }^{4}$ Jiangxi Feiyu Bamboo stock Co., LTD, Fengxin, China
}

\begin{abstract}
Six specimens were made and tested to study the mechanical properties of LBL beams. The mean ultimate loading value is $68.39 \mathrm{MPa}$ with a standard deviation of $6.37 \mathrm{MPa}$, giving a characteristic strength (expected to be exceeded by $95 \%$ of specimens) of $57.91 \mathrm{MPa}$, and the mean ultimate deflection is $53.3 \mathrm{~mm}$ with a standard deviation of $5.5 \mathrm{~mm}$, giving the characteristic elastic modulus of $44.3 \mathrm{~mm}$. The mean ultimate bending moment is $20.18 \mathrm{kN} . \mathrm{m}$ with a standard deviation of $1.88 \mathrm{kN} . \mathrm{m}$, giving the characteristic elastic modulus of $17.08 \mathrm{kN}$.m. The mean elastic modulus is $9688 \mathrm{MPa}$ with a standard deviation of $1765 \mathrm{MPa}$, giving the characteristic elastic modulus of $6785 \mathrm{MPa}$, and the mean modulus of rupture is $93.3 \mathrm{MPa}$ with a standard deviation of $8.6 \mathrm{MPa}$, giving the characteristic elastic modulus of 79.2 MPa. The strain across the cross-section for all LBL beams is basically linear throughout the loading process, following standard beam theory.
\end{abstract}

\section{Introduction}

Laminated bamboo lumber (LBL) is one kinds of engineered bamboo materials which could be used in structural engineering. More and more scientists are interested in LBL and some studies have been done [1$11]$.

Some researchers have investigated the basic mechanical properties of LBL. Tensile, compressive and bending performance of layered laminate bamboo composite (LLBC) have been studied by Verma and Charier [12], and the specimens have a cross-section of $16 \mathrm{~mm} \times 10 \mathrm{~mm}$. Yeh and Lin [13] investigated how the growth height influence the bending strength of LBL, and both un-jointed and jointed specimens with the length of $1000 \mathrm{~mm}$ and the cross-section of $30 \mathrm{~mm} \mathrm{x}$ $30 \mathrm{~mm}$ have been tested. Considering the glue spread rate and moisture content influencing factors, Lee et al. [14] studied the bending properties of 24 laboratorymanufactured LBL specimens, and found the elastic modulii ranging from $7411 \mathrm{MPa}$ to $9204 \mathrm{MPa}$ and rupture strengths between $67.7 \mathrm{MPa}$ and 107.2 $\mathrm{MPa}$.

As for the structural elements, $\mathrm{Li}$ et al. [15-20] examined the mechanical performance for the columns in detail, and proposed a tri-linear model with an elastic portion, and elasto-plastic portion and a purely plastic portion. A fine stress-strain relationship model for LBL under axial compression was also put forward by Li et al. [16] based on the short compression tests. Considering many influencing factors, both the LBL columns under axial compression and eccentric compression have been investigated by Li et al. [17-20], and the ultimate bearing capacity calculation equations were proposed. The axial compression performance of LBL column piers along three directions were studied and compared by $\mathrm{Su}$ et al. [21], and the relationship models for load-axial displacement along three compression directions could be used the same tri-linear model.

As for the structural beam members, Sinha et al. [22] evaluated the potential application for the laminated bamboo lumber (LBL) and bamboo glulam beams (BGBs)'s in structures. Li et al. [23-26] also investigated the mechanical performance for LBL beams considering the influencing factors of shear span ratio and height to width ratio, and the ultimate load calculation equations were proposed. Zhang et al. [23-26] has studied how AFRP efect on parallel bamboo strand lumber beams.

As mentioned above, even though some studies about LBL beams have been done by some researchers, the work is still limit and more research on the mechanical properties of LBL beams need to be done. Thus, this study examines in detail at the behaviour of specimens constructed from laminated bamboo lumber.

\section{Materials and test methods}

\subsection{Specimens}

The lower growth portion of the Moso bamboo (Phyllostachys pubescens, from Fujiang province) tubes were chosen with the age of 3-5 years to produce the specimens. After removing the outer skin (epidermal)

* Corresponding author: 1687699888@qq.com 
and inner cavity layer (pith peripheral) by a planer, all the culm strips were then dried and charred. With the final thicknesses of $7 \mathrm{~mm}$ and the widths of $21 \mathrm{~mm}$, the strips were produced and made into laminated bamboo lumbers. Six beam specimens were made with the size of $50 \mathrm{~mm} \times 160 \mathrm{~mm} \times 1960 \mathrm{~mm}$ and the cross-section for the beam specimen could be seen from Fig. 1 .

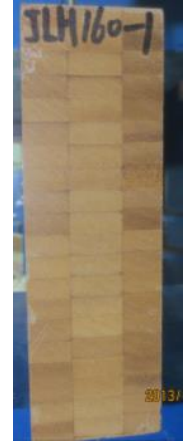

Fig. 1. Cross-section for beam specimen

\subsection{Test methods}

The beam test arrangement could be illustrated in Fig. 2 . Five Laser Displacement Sensors were arranged to measure the displacements of the specimen. The beams were strain gauged longitudinally at the middle cross section, with five strain gauges pasted on one side face at even spacing through the depth, and one strain gauge pasted on each of the bottom face and the top face, as shown in Fig. 2. A microcomputer-controlled electrohydraulic servo universal testing machine (Fig. 3) with a capacity of $300 \mathrm{kN}$ was chosen for the beam tests. Fourpoint loading method was used for the tests and the clear span for the beam is $1770 \mathrm{~mm}$. All beam specimens were divided into three even parts by four loading points.

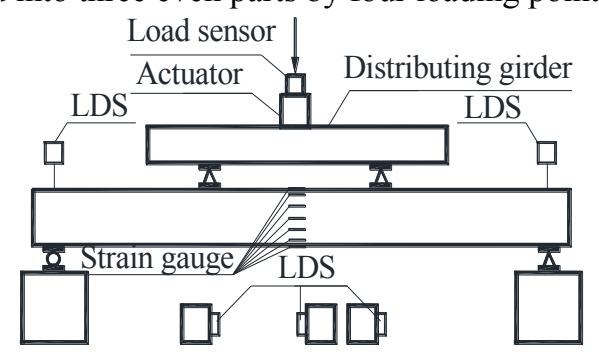

Fig. 2. Test scheme for beam specimen

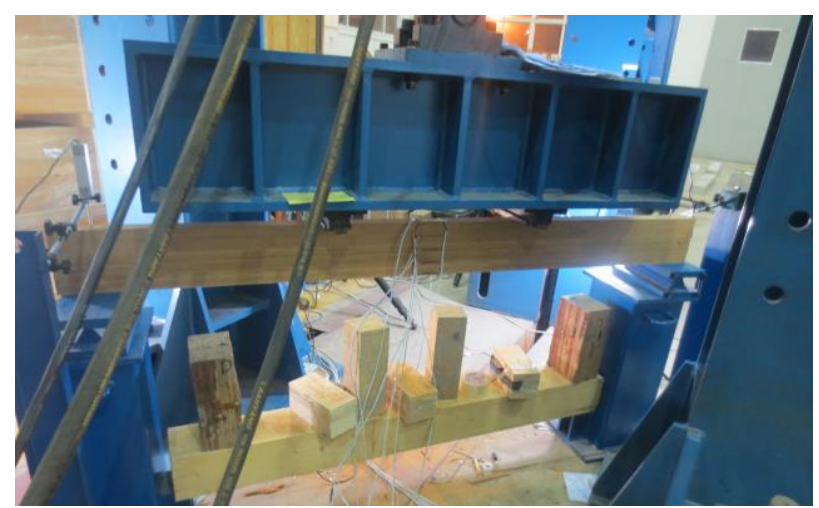

Fig. 3. Test photos for beam specimen
All beam specimens behaved elastically at the loading beginning, and then showed a small amount plastic deformation with the increasing of loading. The stiffness of the beams decreased. As the vertical displacement became bigger and bigger, cracks (accompanied by a slight noise) appeared on the bottom surface of the beam. All test specimens split along the longitudinal direction once the outer bottom surface strips separated along the depth direction, and the whole specimen was damaged quickly. Cracks always started at the natural bamboo joint area on the tensile surface but none clear failure could be found in the top surface. Brittle tensile failure happened to all test specimens. The final failure photos for the top surface, bottom surface and two side surfaces could be seen from Fig. 4 .

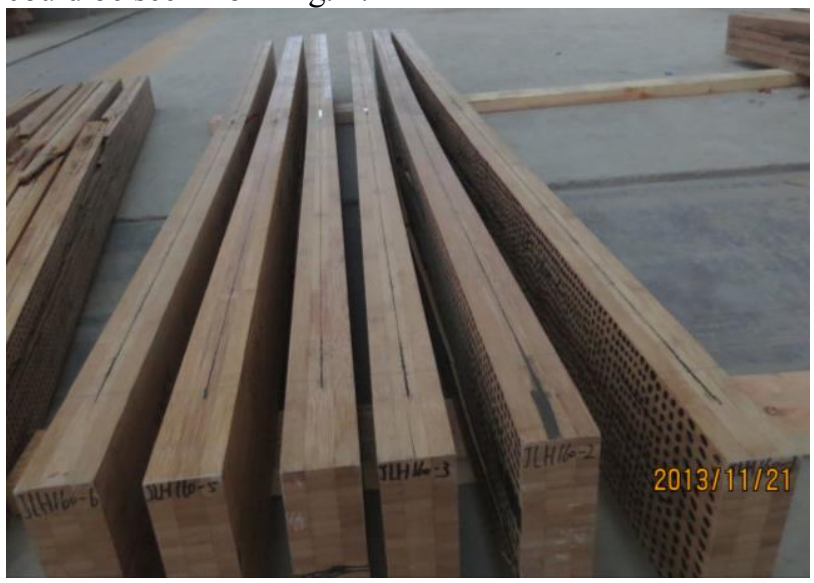

(a) Top surface

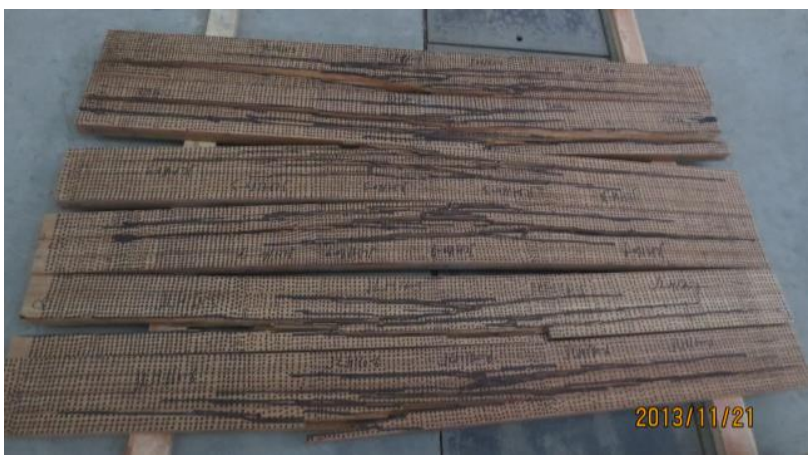

(b) One side surface

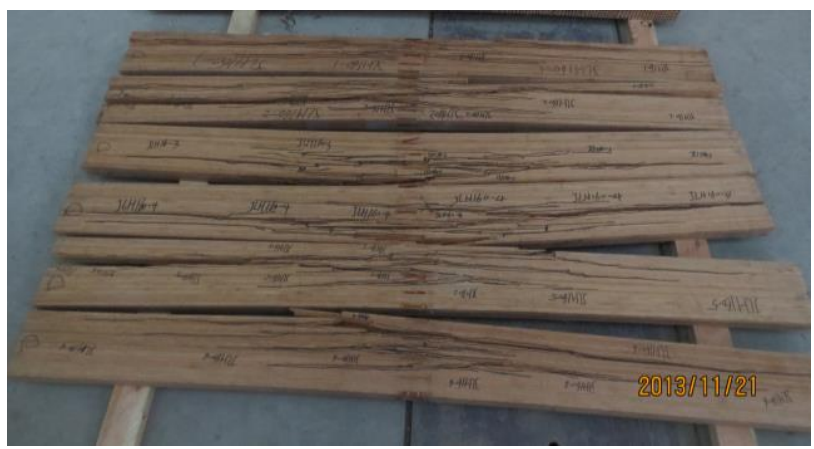

(c) The other side surface

\section{Failure Analysis}




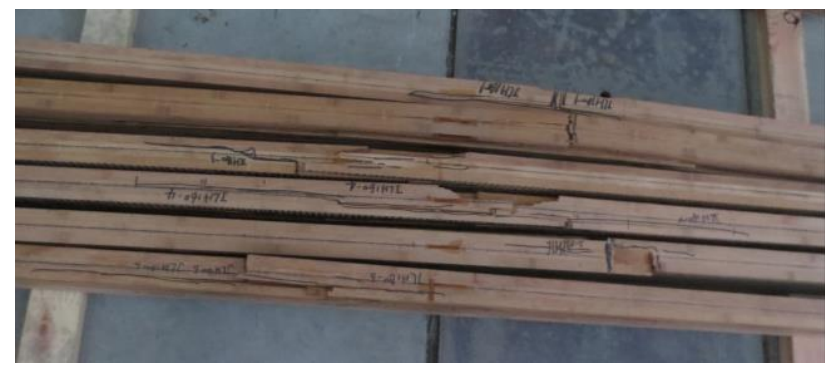

(d) Bottom surface

Fig.4. Failure photos for the beams

\section{Test results and combined analysis}

\subsection{Test results}

The test results for six beam specimens are presented in table 1. SDV means standard deviation; COV means coefficient of variation; CHV means characteristic value, calculated on the basis that $95 \%$ of samples will exceed the characteristic value (mean ultimate value $-1.645 \mathrm{x}$ standard deviation). $F_{\max }$ is the maximum bending load; $w$ is the ultimate deflection; $\mathrm{M}$ is the ultimate bending moment; the modulus of elasticity (MOE) and the modulus of rupture (MOR) were calculated using Eqs. (1) and (2), respectively

$$
\begin{gathered}
\mathrm{MOE}=\frac{a \Delta F}{48 I \Delta w}\left(3 L^{2}-4 a^{2}\right) \\
\mathrm{MOR}=\frac{3 F_{\max } a}{b h^{2}}
\end{gathered}
$$

Where $a$ is the distance between loading support and loading points which is $590 \mathrm{~mm}$ for these tests; $\Delta F$ is the load increment in elastic stage; $w$ is the ultimate deflection of the middle span point; $\Delta w$ is the deflection of the middle span point under $\Delta F ; L$ is the span of the beam which is $1770 \mathrm{~mm}$ for the tests; $I$ is the moment of inertia of the beam; $F_{\max }$ is the maximum bending load; $b$ is the width which is $50 \mathrm{~mm}$; and $h$ is the height of the beam cross-section which is $160 \mathrm{~mm}$.

Table 1. Test results for group JLH180

\begin{tabular}{cccccc}
\hline Specimen & $\begin{array}{c}F_{\max } \\
/ \mathrm{kN}\end{array}$ & $\begin{array}{c}w \\
/ \mathrm{mm}\end{array}$ & $\begin{array}{c}\mathrm{M} \\
/ \mathrm{kN} . \mathrm{m}\end{array}$ & $\begin{array}{c}\mathrm{MOE} \\
/ \mathrm{MPa}\end{array}$ & $\begin{array}{c}\mathrm{MOR} \\
/ \mathrm{MPa}\end{array}$ \\
\hline JLH160-1 & 61.63 & 44.7 & 18.18 & 9219 & 84.1 \\
JLH160-2 & 78.83 & 56.8 & 23.26 & 10057 & 107.4 \\
JLH160-3 & 68.79 & 54.0 & 20.29 & 10104 & 93.7 \\
JLH160-4 & 72.35 & 61.1 & 21.34 & 11427 & 98.8 \\
JLH160-5 & 64.49 & 52.4 & 19.03 & 6435 & 88.2 \\
JLH160-6 & 64.25 & 51.1 & 18.95 & 10887 & 87.8 \\
Mean & 68.39 & 53.3 & 20.18 & 9688 & 93.3 \\
SDV & 6.37 & 5.5 & 1.88 & 1765 & 8.6 \\
COV & 0.09 & 0.10 & 0.09 & 0.18 & 0.09 \\
CHV & 57.91 & 44.3 & 17.08 & 6785 & 79.2 \\
\hline
\end{tabular}

According to these 6 beam specimens, the mean ultimate loading value is $68.39 \mathrm{MPa}$ with a standard deviation of $6.37 \mathrm{MPa}$, giving a characteristic strength (expected to be exceeded by $95 \%$ of specimens) of 57.91 $\mathrm{MPa}$, and the mean ultimate deflection is $53.3 \mathrm{~mm}$ with a standard deviation of $5.5 \mathrm{~mm}$, giving the characteristic elastic modulus of $44.3 \mathrm{~mm}$. The mean ultimate bending moment is $20.18 \mathrm{kN}$.m with a standard deviation of 1.88 $\mathrm{kN}$.m, giving the characteristic elastic modulus of 17.08 kN.m. The mean elastic modulus is $9688 \mathrm{MPa}$ with a standard deviation of $1765 \mathrm{MPa}$, giving the characteristic elastic modulus of $6785 \mathrm{MPa}$, and the mean modulus of rupture is $93.3 \mathrm{MPa}$ with a standard deviation of 8.6 $\mathrm{MPa}$, giving the characteristic elastic modulus of 79.2 $\mathrm{MPa}$.

\subsection{Load-displacement response}

The load-displacement curves for beam specimens could be seen from Fig. 5. The load-displacement response is consistency in the original elastic stage. When the loading value was bigger than $28 \mathrm{kN}$, five curves kept good consistency except one curve.

Micro-cracks within the material were audible and are also observed in small drops along the loaddisplacement curves for all test specimens, no cracks were visible before the ultimate state. The overall behaviour for all the beams is substantially the same, with an initial elastic response followed by non-linear softening, and a brittle failure.

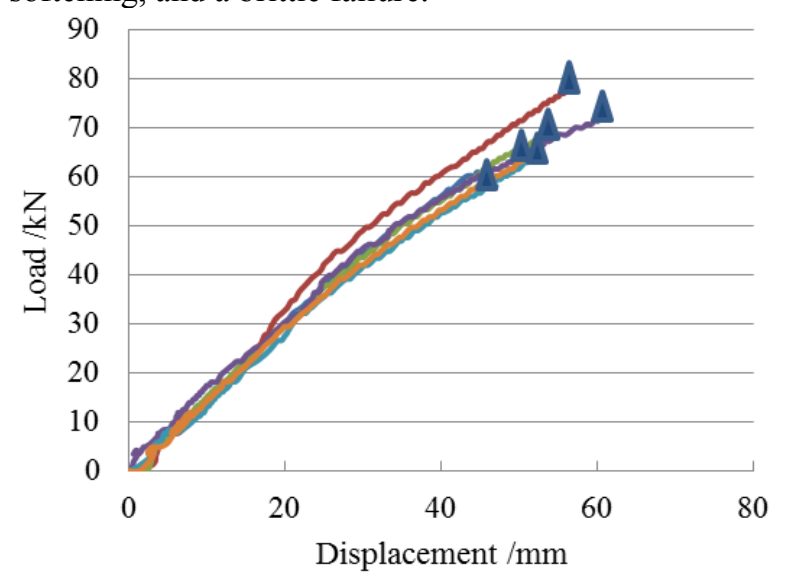

Fig.5. Load-displacement responses

\subsection{Strain profiles}

The strain profiles through the loading for the mid-span cross-section for all test beams could be seen from Fig. 6 . The strain across the cross-section for all LBL beams is basically linear throughout the loading process, following standard beam theory. 


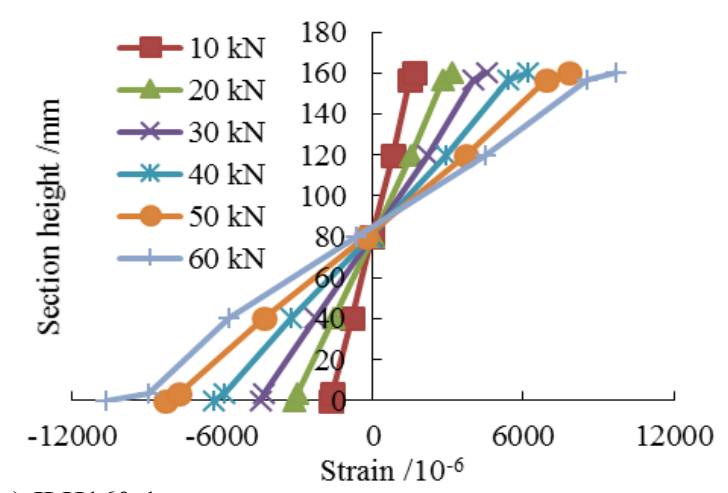

(a) JLH160-1

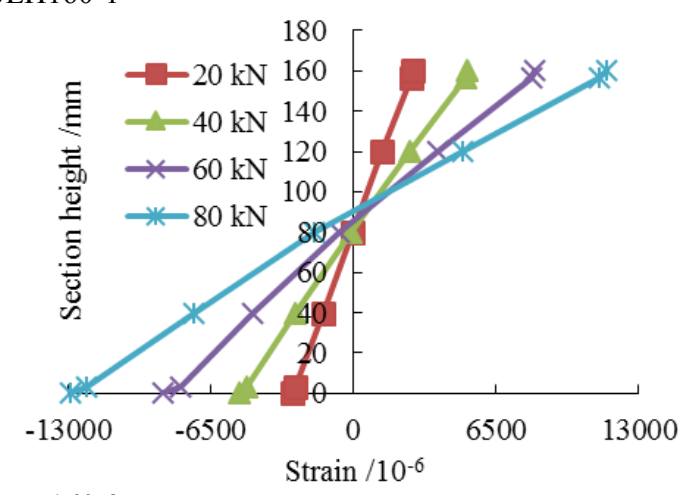

(b) JLH160-2

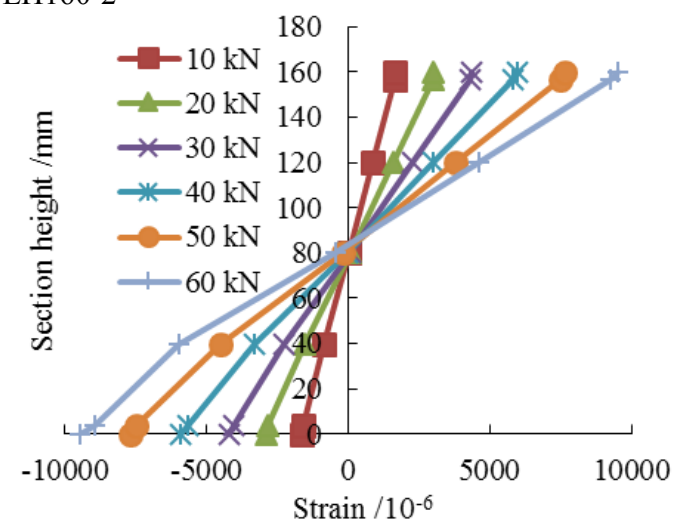

(c) JLH160-3

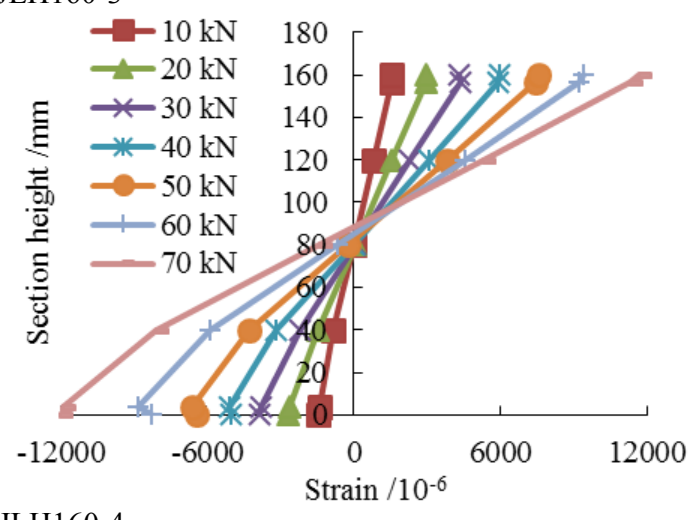

(d) JLH160-4

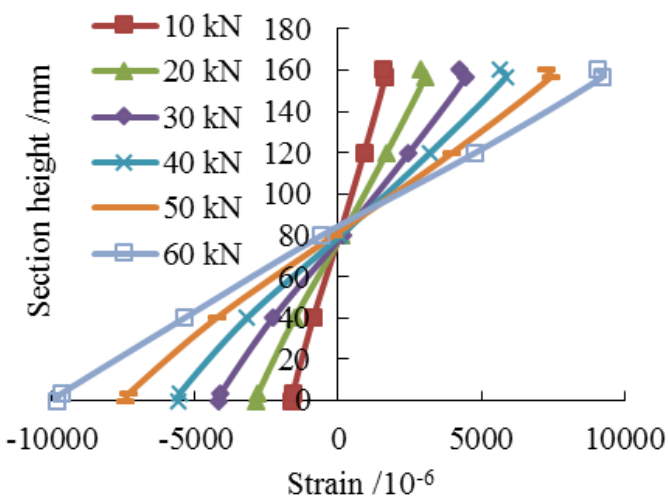

(e) JLH160-5

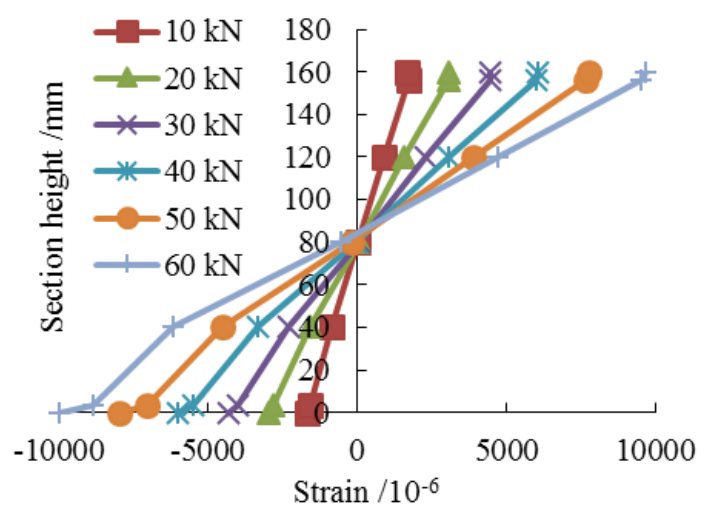

(f) JLH160-6

Fig.6 Typical strain profile development for the mid-span cross-section

\section{Conclusions}

Six specimens were made and tested to study the mechanical properties of LBL beams. According to analysis of the test data, the following conclusions can be drawn.

(1) Characterized by brittle tensile failure, all LBL beams experienced three stages which are elastic stage, elastic-plastic stage and damaged stage.

(2) The mean ultimate loading value is $68.39 \mathrm{MPa}$ with a standard deviation of $6.37 \mathrm{MPa}$, giving a characteristic strength (expected to be exceeded by $95 \%$ of specimens) of $57.91 \mathrm{MPa}$, and the mean ultimate deflection is $53.3 \mathrm{~mm}$ with a standard deviation of $5.5 \mathrm{~mm}$, giving the characteristic elastic modulus of $44.3 \mathrm{~mm}$. The mean ultimate bending moment is $20.18 \mathrm{kN} . \mathrm{m}$ with a standard deviation of $1.88 \mathrm{kN} . \mathrm{m}$, giving the characteristic elastic modulus of $17.08 \mathrm{kN}$.m. The mean elastic modulus is 9688 $\mathrm{MPa}$ with a standard deviation of $1765 \mathrm{MPa}$, giving the characteristic elastic modulus of $6785 \mathrm{MPa}$, and the mean modulus of rupture is $93.3 \mathrm{MPa}$ with a standard deviation of $8.6 \mathrm{MPa}$, giving the characteristic elastic modulus of $79.2 \mathrm{MPa}$.

(3) The strain across the cross-section for all LBL beams is basically linear throughout the loading process, following standard beam theory.

This work was financially supported by the National University students practical and innovation training project (No. 201710298056Z), the Project of Ministry of Housing and 
Urban-Rural Development of the People's Republic of China (No. 2014K4023), Project of the Housing and Urban-Rural Development Bureau of Jiang-su Province (No. JS2012ZD34), practical and innovation training project of Nanjing Forestry University (2017NFUSPITP180, 2017NFUSPITP182, 2017NFUSPITP183), and a Project Funded by the Priority Academic Program Development of Jiangsu Higher Education Institutions.

\section{References}

1. J. Su, F. Wu, H. Li, P. Yang. Experimental research on parallel bamboo strand lumber column under axial compression. China Sciencepaper, 39-41, 10 (2015).

2. H. Li, J. Su, D. Wei, Q. Zhang, G. Chen. Comparison study on parallel bamboo strand lumber under axial compression for different directions based on the large scale. J. Zhengzhou Univ. (Eng. Sci.), 67-72, 37 (2016).

3. Z. Yu, Z. Wu, T. Su. Microstructure analysis of the coating permeability of laminated bamboo panel for furniture. J. Forestry Sci., 130-134, 1 (2016).

4. G. Chen, T. Zhou, C. Li, Q. Zhang, H. Li. Experimental study on the OSB webbed bamboo beams. J Nanjing Forestry Univ (Nat Sci Ed), 121125, 40 (2016).

5. W. Zhang, W. Jiang, R. Tang. Study on short-term bending creep behavior and microstructure of bamboo scrimber. J. Forestry Sci., 33-37, 2 (2017).

6. M. Huang, X. Zhang, W. Yu, et al. Mechanical properties and structure characterization of bamboo softened by high temperature steam. J. Forestry Sci., 64-68, 1 (2016).

7. Y. Li, B. Xu, Q. Zhang, et al. Present situation and the countermeasure analysis of bamboo timber processing industry in China. J. Forestry Sci., 2-7, 1 (2016).

8. H. Li, J. Su, AJ. Deeks, Q. Zhang, D. Wei, C. Yuan. Eccentric compression performance of parallel bamboo strand lumber column. BioResources, 70657080, 10 (2015).

9. H. Li, D. Wei, J. Su, C. Yuan, G. Chen. Experimental study on PSBL under eccentric compression. J. Build. Mater., 561-565, 19 (2016).

10. S. Zhang, C. Li, Z. Xiao, et al. Bending strength and loading simulation analysis of bamboo scrimber Ishaped beam. J. Forestry Sci., 125-129, 2 (2017).

11. H. Li, Q. Zhang, G. Wu, X. Xiong, Y. Li. Review on laminated bamboo lumber. J. Forestry Sci., 110116, 1 (2016).

12. CS.Verma, VM. Chariar. Stiffness and strength analysis of four layered laminate bamboo composite at macroscopic scale. Compos. part B-Eng., 369-376, 45 (2013).

13. M. Yeh, Y. Lin. Finger joint performance of structural laminated bamboo member. J. Wood Sci., 120-127, 58 (2012).
14. AWC. Lee, XS. Bai, AP. Bangi. Selected properties of laboratory-made laminated-bamboo lumber. Holzforschung, 207-210, 52 (1998).

15. H. Li, Q. Zhang, D. Huang, AJ. Deeks. Compressive performance of laminated bamboo. Compos. part BEng., 319-328, 54 (2013).

16. H. Li, Q. Zhang, G. Wu. Stress-strain model under compression for side pressure laminated bamboo. J. Southeast Univ. (Nat Sci.), 1130-1134, 45 (2015).

17. H. Li, J. Su, Q. Zhang, AJ. Deeks, D. Hui. Mechanical performance of laminated bamboo column under axial compression. Compos. part BEng., 374-382, 79 (2015).

18. H. Li, G. Wu, Q. Zhang, J. Su. Mechanical evaluation for laminated bamboo lumber along two eccentric compression directions. J. Wood Sci., 503517, 62 (2016).

19. H. Li, G. Chen, Q. Zhang, M. Ashraf, B. Xu, Y. Li. Mechanical properties of laminated bamboo lumber column under radial eccentric compression. Constr. Build. Mater., 644-652, 121 (2016).

20. H. Li, G. Wu, Q. Zhang, G. Chen. Experimental study on side pressure LBL under tangential eccentric compression. J Hunan Univ (Nat Sci.), 9096, 43 (2016).

21. J. Su, H. Li, P. Yang, Q. Zhang, G. Chen. Mechanical Performance Study on laminated bamboo lumber column pier under axial compression. China Forestry Sci. Technol., 89-93, 29 (2015).

22. A. Sinha, D..Way and S. Mlasko. "Structural performance of glued laminated bamboo beams," J. Struct. Eng-ASCE, 04013021, 140 (2014).

23. H. Li, J. Su, Q. Zhang, G. Chen. Experimental study on mechanical performance of side pressure laminated bamboo beam. J. Build. Struct., 121-126, 36 (2015).

24. H. Li, AJ. Deeks, Q. Zhang, G. Wu. Flexural performance of laminated bamboo lumber Beam. BioResources, 929-943, 11 (2016).

25. H. Li, G. Wu, Q. Zhang, AJ. Deeks, J Su. Ultimate bending capacity evaluation of laminated bamboo lumber beams. Constr. Build. Mater., 365-375, 160 (2018).

26. H. Zhang, H. Li, I. Corbi, O. Corbi, G. Wu, C. Zhao, T. Cao. AFRP influence on parallel bamboo strand lumber beams. Sensors, 2854, 18 (2018). 